\title{
Ambiguous Absence, Ambiguous Presence: A Qualitative Study of Military Reserve Families in Wartime
}

\author{
Anthony J. Faber \\ Southeast Missouri State University
}

\author{
Elaine Willerton, Shelley R. Clymer, \\ Shelley M. MacDermid, and Howard M. Weiss \\ Purdue University
}

\begin{abstract}
The "Global War on Terrorism" has resulted in reservists being deployed at an everincreasing rate. However, because reservists and their families are unaccustomed to deployments, many families may experience boundary ambiguity, a state in which family members are uncertain in their perception about who is in or out of the family and who is performing which roles and tasks within the family. This qualitative description study examined boundary ambiguity in military reserve families over time. A sample of 34 reservists, spouses, and parents was interviewed 7 times within the 1st year of the reservists' return from Iraq. During deployment, all family members experienced boundary ambiguity. Gathering information and attending a family support group provided some relief for families. After the reservists returned, couples as well as those who had experienced additional life events or losses experienced the highest levels of boundary ambiguity. However, this boundary ambiguity dissipated over time, as families tended to restabilize once the reservists had returned to work and a routine had been established.
\end{abstract}

Keywords: ambiguous loss, boundary ambiguity, military families, military deployments, military reunions

Today, it is estimated, over 152,000 military members are deployed to the Middle East, with approximately 80,000 reservists and National Guard troops deployed to over 40 nations (Global Security, 2007). Since the "Global War on Terrorism" began (Coalition Information Centers, 2001), over 378,000 reservists have been deployed (U.S. Government Accountability Office, 2006). Reservists currently comprise $31 \%$ of the total military force (Military Homefront, 2005), and, as a result of the downsizing of the active duty force in the 1990s, they play a central role, which results in more frequent and lengthier deployments (Quadrennial Defense Review, 2002). Deployment-related separations and reunions have been identified as major stressful events for military families (Bell \& Schumm, 1999; Wood, Scarville, \& Gravino, 1995).

Spouses of military members have reported that deployments result in loss of emotional support, loneliness, role

Anthony J. Faber, Department of Human Environmental Studies, Southeast Missouri State University; Elaine Willerton, Shelley R. Clymer, and Shelley M. MacDermid, Department of Child Development and Family Studies, Purdue University; Howard M. Weiss, Department of Psychology, Purdue University.

Preparation of this article was supported in part by Cooperative Agreement DASW01-00-2-0005, which was awarded to Shelley M. MacDermid and Howard M. Weiss by the U. S. Department of Defense.

Correspondence concerning this article should be addressed to Anthony J. Faber, Southeast Missouri State University, One University Plaza, Department of Human Environmental Studies MS5750, Cape Girardeau, MO 63703. E-mail: afaber@semo.edu overload, role shifts, and concerns about the safety and well-being of the deployed military members (Bell \& Schumm, 1999; Vormbrock, 1993; Wood et al., 1995). Spouses also report substantial difficulties in getting reliable and timely information about their deployed husband or wife. In a study of deployments to Somalia (Kerner-Hoeg, Baker, Lomvardias, \& Towne, 1993), $70 \%$ of military spouses reported technical and logistical difficulties in communicating with deployed military members, and $80 \%$ reported fears about soldiers' safety, living conditions, and physical health. According to Kerner-Hoeg et al. (1993), 9 out of 10 spouses reported stress as a function of their uncertainty about what the future would bring.

A military member's return home, although joyous, can also be very stressful for families. Both military members and spouses have to readjust to one another and to accept the fact that it will be nearly impossible to simply resume life exactly as it was before the deployment (Bell \& Schumm, 1999). Many soldiers have reported that it is stressful to have to renegotiate roles, responsibilities, and boundaries with their spouse (Caliber Associates, 1992; Drummet, Coleman, \& Cable, 2003; Riggs, 1990). Even young veterans who are deployed as adolescents face stress upon their return, as they must resume the family life cycle stage of individuation from their families and renegotiation of boundaries (Yerkes \& Holloway, 1996).

Reunion is also stressful if the service member is experiencing symptoms of posttraumatic stress disorder (PTSD), which can include nightmares and flashbacks, withdrawal from activities, and detachment from others, all of which can inhibit the reconnection to family members (Hogan- 
camp \& Figley, 1983). Reservists tend to have higher prevalence rates of PTSD than do active duty soldiers (Stretch et al., 1996). In a recent survey of Army and Marine soldiers returning from Iraq, PTSD rates were $18 \%$ and $20 \%$, respectively (Hoge et al., 2004).

Reservists and their families are a unique subpopulation within the armed forces and may encounter additional stressors related to deployment and reunion. In comparison with active duty military members, who often live on or near military installations and who receive military training daily, reservists live and work in the civilian community and receive military training 1 weekend a month. As a result, reservist families are less likely to be integrated into a military social support network, are less familiar with how to access the military benefits to which they are entitled, and are less likely to use installation-based social services (Segal \& Segal, 2003). In addition, when called to duty, reservists and their families are not as prepared to deploy quickly and may experience a drop in income, particularly if a reservist has a high-paying civilian job (Caliber Associates, 1993). For reservists deployed during Operation Desert Storm/Shield, the biggest stressor reported was a drop in income as well as not receiving timely military pay (Dunning, 1996).

Due to a variety of factors, deployments and reunions do not affect all families in the same way. Personal characteristics and levels of social support have been found to buffer the effects of deployment (Lavee, McCubbin, \& Patterson, 1985; Rosen \& Moghadam, 1990; Wood et al., 1995). Typically, families that have the most difficulty adapting to deployments and reunions are thought to be those whose members are young, newly married, financially unstable, and experiencing their first deployment (Rienerth, 1978; Rohall, Segal, \& Segal, 1999).

According to McCubbin and colleagues, military family adaptation to stressful events depends upon family resources and strengths, the "pileup" of demands on the family system, and family perceptions of the situation (Lavee et al., 1985; McCubbin \& Patterson, 1983). Boss (1986) argued that a stressor does not act directly on the family; rather, "it is the perception of the event as mediated by internal and external contexts that determines whether the family will cope or fall into crisis" (p. 270).

Boss's concept of ambiguous loss, which refers to ambiguous events or situations that entail a loss or separation, is useful for understanding military deployments and reunions, because it goes beyond the event itself to take into account one's perceptions of the event to help explain adjustment. Psychologically, ambiguous loss can be a problem, in that it can create feelings of hopelessness, uncertainty, and confusion that can lead to depression, guilt, anxiety, and immobilization (Boss, 2004). Structurally, ambiguous loss can be a problem when it leads to boundary ambiguity, described as "a state in which family members are uncertain in their perception about who is in or out of the family and who is performing what roles and tasks within the family system" (Boss \& Greenberg, 1984, p. 536).

Boss (2002) identified two types of ambiguous loss: ambiguous absence and ambiguous presence. Ambiguous absence occurs when a person is perceived by his or her family members as being physically absent but psychologically present. The family often becomes preoccupied with the lost or absent relative, and it becomes unclear which roles family members play. Drummet et al. (2003) stated that family members must stretch the family boundary enough both to psychologically retain the service member as a viable family member and to temporarily reassign his or her responsibilities.

Ambiguous presence occurs when a family member is perceived as being physically present but psychologically absent. During reunion, although physically present, the family member may be psychologically absent, as a result of trauma from past experiences as well as of the distress from immediate resumption of previous roles and responsibilities. Thus, deployments and reunions may cause military families to experience ambiguous absence and ambiguous presence consecutively.

Although numerous studies have examined adjustment to deployments and reunions, few studies have examined such adjustment using the framework of ambiguous loss. In addition, little is known about the longitudinal course of boundary ambiguity and how it is resolved over time. Lastly, Boss (2002) suggested that families that frequently have a member absent for periods of time due to work (such as employment as an oil rigger or as an active duty military member) may have learned to tolerate ambiguous loss without boundary ambiguity. Although this might be true for active duty military families that have experienced several deployments, reservists and their families have rarely experienced deployments. Thus, reservists and their families may constitute an important source of information about the occurrence of boundary ambiguity within families.

We propose the following research questions: (a) What is the longitudinal course of ambiguous loss for military families in the reserve component? and (b) How and with what results do military families in the reserve component cope with ambiguous loss over time?

\section{Method}

\section{Participants}

We used a maximum variation sampling strategy (Patton, 2002) that resulted in data from both reservists (16 total) and a family member (spouse, significant other, or parent; 18 total). Not all reservists in this study were married or cohabiting; therefore, we included parents as family members for single reservists, as the parents seemed to experience ambiguous loss. We also wanted to explicitly acknowledge the influence of parents on reservist adjustment to deployment and reunion. All participants were recruited from an Army Reserve unit of 119 members that was deployed to Iraq for 15 months early in 2003. All participants were deployed together in February 2003 and returned to the United States in April 2004. Although the unit was based in the Midwest, 25\% of the deployed reservists were activated from around the country to fill empty positions within the unit. 
Following university institutional review board (IRB) approval, we recruited participants using several strategies, including a presentation at a family support group meeting; information packets in the mail; and a presentation to reservists during the first debriefing meeting following their return, which was attended by 57 reservists. Military IRB approval was not required at the time, because the research was not conducted at a Department of Defense facility. However, this policy has recently been clarified; it now states that all research involving the military population requires military IRB approval. Additional recruitment attempts were made at 4 months and 11 months into the study via a newsletter. Reservists and family members who were interested in participating informed the researchers by telephone, e-mail, or postcard. Participants were accepted for the study regardless of whether another member of their family agreed to participate.

A total of 16 reservists and 18 family members participated. Of the reservists, 14 were male and 2 were female, with an average age of $29(S D=8.7)$ years. Eighty-seven percent of those sampled were Caucasian; the remaining participants were African American. Fifty percent of the reservists were married, $12 \%$ were separated, $19 \%$ were cohabitating, and $19 \%$ were single; $56 \%$ had children. On average, the reservists had some college education and had been in the military for 8 years. For all but 2 reservists, this had been their first deployment.

Taking into account the 18 family members who participated, our sample consisted of 10 matched soldier-spouse pairs, 4 matched soldier-parent pairs, and 2 unmatched family members from each group. The average age of family members was 38 years $(S D=12.5) ; 16$ of the family members were female, and $89 \%$ and $11 \%$ were Caucasian and African American, respectively. The average education level was some college, and average annual household income was $\$ 40,000$. Family members had been part of a military family for an average of 9 years, with this deployment being the first for all but 2 of the family members.

\section{Procedure}

Seven waves of interviews were conducted during the year following the reservists' return from deployment. The first interview was conducted within 3 weeks of the reservists' return. The other six interviews occurred at 4, 6, 12, 24, 36 , and 52 weeks following return. The time intervals between interviews lengthened over the course of the year, because we anticipated that rates of change would slow with time (Pincus, House, Christenson, \& Adler, 2006). Attrition rates were moderate, with 26 of the 34 individuals participating in three or more of the interviews. Of the 16 reservists in our study, 6 completed all seven interviews, and 7 of the 18 family members completed all seven interviews.

The current study was conducted as part of a larger study on military families that utilized interview questions in the areas of stressors, coping mechanisms, marital relationship, parent-child relationship, friendships, and social support (e.g., What do you think will be the most positive aspects of having your family member back home? The least positive aspects? Do you have any strategies for how to adjust to being back together?). The interviews were semistructured, with the same set of questions being asked at each wave. In-home, face-to-face interviews were conducted for those participants living nearby, and telephone interviews were conducted for those living outside the area. Reservists and their family members were interviewed separately at times convenient for them.

Interviewers were graduate students and faculty from the departments of family studies, psychology, and human resource management. All interviewers attended a 4-hr training seminar, which was hosted by the project managers and a qualitative researcher, to learn interview protocol, procedures, and interview techniques. Most participants were interviewed by the same person at each time point. Participants were sent inexpensive tokens of appreciation (e.g., keychains) and handwritten thank-you notes after each interview. All interviews were audiotaped and were transcribed verbatim.

\section{Data Analysis}

We used a qualitative description method to analyze the data in terms of understanding theory-derived concepts (e.g., boundary ambiguity), patterns, themes, and emergent understandings (Sandelowski, 2000; Sullivan-Bolyai, Bova, \& Harper, 2005). Using the strategies suggested by Miles and Huberman (1994) and Saldana (2003), we sought to manage and organize our data by creating a thematic conceptual matrix and a time-ordered matrix for each participant. These matrices contained a description at each wave of the reported stressors, role changes, life events, coping strategies, and general themes, as well as a quantitative item regarding how the individual rated his or her overall adjustment to reunion (as high, medium, or low) at that time point.

The participants' perceptions of boundary ambiguity were rated at each point in time. Boundary ambiguity was assessed in relation to the return of the reservist to civilian employment and to his or her work environment, as well as in relation to the division of household roles and tasks at home. In addition, boundary ambiguity was assessed in the area of relationships between reservist and spouse, significant other, or parent regarding confusion in their relations with one another or confusion about the perceived emotional availability of family members. Participants received a high, medium, or low rating in each of the three areas of life.

We utilized an iterative process to ensure good interrater reliability. First, two raters read the transcripts for each participant and rated the level of boundary ambiguity. The raters were independent and were blind to the other ratings. Reliability across the ratings was checked, and discrepancies were discussed. This process was repeated, and sufficient reliability among the raters was found. We calculated Cohen's kappa (Cohen, 1960) to determine the level of interrater reliability. Kappa values for reservists' work, roles, and relationships were $.81, .76, .79$, respectively. Kappa values of .75 or greater signify excellent agreement (Fleiss, 1973). 
Because the Wave 1 interview was the only interview that inquired about the deployment, we conducted a cross-case analysis of all 34 individuals who participated at Wave 1 that identified emergent themes related to ambiguous absence and boundary ambiguity during deployment. Next, we examined ambiguous presence during reunion, as well as the changes in boundary ambiguity over time. For this, we conducted a within-case analysis of the 26 individuals who had participated in three or more interviews. We repeatedly reviewed each participant's matrix, looking for evidence of ambiguous presence as well as fluctuations over time in his or her ratings of boundary ambiguity. We then sought to identify and to understand emergent themes found across participants.

\section{Results}

\section{Deployment-Ambiguous Absence}

The longitudinal course of ambiguous loss occurred in two phases. The first phase began for families during deployment, and the second phase occurred following reunion. We found that, during deployment, family members had experienced ambiguous absence, which lasted throughout deployment and was characterized by the reservist's psychological presence but physical absence within the family. The major themes uncovered from interviews with family members about the deployment phase revealed boundary ambiguity around safety, redistribution of roles and responsibilities, and rejoining the family.

Safety. Family members reported that, during deployment, they thought about their reservist constantly and worried about his or her safety. Boundary ambiguity was elevated when the family members heard of bombings or attacks. Families attempted to stay in frequent contact; however, the stress generated by the boundary ambiguity was exacerbated by the lack of information they had regarding their reservist. Family members reported their biggest stressor to be the unknowns and lack of control in terms of whether the reservist was alive, dead, or injured. They worried about where the reservist was located, the level of danger, what the reservist was doing, and when he or she would be returning home. Rose, a mother, described her perceived boundary ambiguity as

the fear of the unknown ... that you have no control over the situation, number one, and then you're kept in the dark by not knowing what's going on. It's far away, and there isn't constant communication, so you just simply don't know what's going on.

Redistribution of roles and responsibilities. Family members, particularly spouses, experienced high levels of boundary ambiguity around family roles and household decisions. Spouses reported that they had to take over the roles of their reservist while he or she was gone and to make many of the decisions regarding household maintenance and other decisions affecting the family. Taking on additional roles and responsibilities was difficult for spouses; as spouses made decisions, they speculated about what the reservist would do and how he or she would react to the decision that had been made. Spouses tried to keep their reservist partially engaged in his or her roles, particularly when the situation entailed making decisions. Often, a spouse's attempt to involve the reservist in a decision resulted in disappointment for the spouse. As Pam, a wife of 8 years, stated,

When we'd write letters back and forth and I would tell him about some of the problems that were going on at home, my answers back [from him] weren't so much how to deal with the problems as "we'll deal with that when I get home." It was stressful that you couldn't get answers about what you should do.

This lack of information seemed to lead to confusion for spouses, both regarding what to do and regarding concern about whether the military member would accept or be disappointed in the decisions once he or she had returned.

Rejoining the family. As the end of deployment drew near, boundary ambiguity for family members shifted from anxiety about their reservist's safety and about household management to worries about reunion. The transition from physical absence to physical presence was characterized by concerns about how the reservist would rejoin the family system, as well as about the reservist's personality and behavior upon return. Some family members expressed concern about conflict with their loved one. For example, Jill, engaged to a reservist, said, "I think I was worried about us fighting, like with him just being different and he's been like away from everything and everyone, and he won't be as tolerable or something ... . will be moodier or something." Jill clearly expressed uncertainty about the effects of the deployment on her partner, saying, "You don't know what to expect; you can't really prepare for it, because you don't know what to expect."

\section{Coping With Ambiguous Absence}

Seeking information from media. Family members attempted to manage their perceptions of boundary ambiguity by seeking information and by using the family support group (FSG; a military-sponsored group for family members in the unit). Family members often reported that they had tried to seek information about the status of their reservist as a way to reduce their stress but that they had struggled to find sources of accurate and timely information, as well as to find how to deal with the information once they had it. Due to the modest communication capabilities in Iraq, most family members had only sporadic conversations with their reservist. Family members reported that when they were able to talk to their reservist, the reservist was often guarded in the information that he or she provided, so as to protect them from worrying. As a result, family members often tried to get information from the news or from the unit administrator who was stationed in the United States. As one wife, Rachael, stated,

I watched the news three times a day, the local news, and when the local news wasn't on, CNN was on, trying to figure out what's going on over there. I was also in contact with the unit administrator frequently, as to where they'd been moved to, how are they doing, and that kind of thing, because the one 
thing I didn't get from my husband while he was gone was talk about where they were at over there and how close to Fallujah [he was], and, you know, what they were seeing. Like as far as the actual war goes, you didn't get any of that, so you know he would always write really relaxing letters, just about "I can't wait to see you, I miss you," that kind of thing. So you basically ... following up with anybody I could that would tell me really the real story going on over there, which we never got.

The constant availability of information from the news seems to have created a bind for many families, in which they sought information to reduce their ambiguity and stress, but too much information actually created additional worry and stress. One mother reflected about her deployment experience: "Then [during deployment], I would have loved to have all this information at the time, just to know, but now that I think about it, I'm glad I didn't. . . . I knew enough just to pacify me and to get me through." Others found themselves drawn to the news, even though it was difficult to watch. "They tell you not to watch [the news], yet it's kind of a love-hate thing," explained Sue, a wife of 1 year. "You don't want to watch it, but you do want to watch it. It's almost mesmerizing." Others had to stop watching the news, because they were obtaining too much information that just created more stress. As Cindy, married for 3 years, stated, "It did get better, once I stopped watching it [the news]. I didn't worry so much about everything, but I didn't know as much about what was going on over there."

FSG. The FSG was another source of information and support, which helped to reduce the ambiguity family members were experiencing. As Amy, a mother, stated,

The FSG told us what to expect. They kept us posted on what was going on with the guys ... kept us informed of what was going on; that took that fear away. So we also, kind of from each other, would get different bits of information that maybe we didn't get everything from our soldier.

The FSG also provided emotional support by putting reservist families in contact with one another. In addition to seeking information as a way to cope with the ambiguous absence, many family members reported seeking emotional support from others who could understand their situation. For many, this type of emotional support could only be found with other families in the unit. As one mother, Nancy, stated, "In regards to the FSG, I can't talk to my family about what's going on because they don't understand. But everybody in the FSG is ... they know, you know? They have been through the exact same thing." Mary, a young woman married to a reservist for 1 year, found that the FSG was a place where she received support and which provided support that made her feel better:

The family support group was really helpful, because I'd go to work and [there would] be, you know, a bunch of people. I'd have, like, a bad day and I'd really miss [the reservist]. [People said] "Oh, I know what you're going through" and I [would] just look [and say] "no, you don't." You know, then I would go to ... FSG and they're just like, "Yeah, I've been going through this," "Yeah, I've been going through that." So, it's like people know exactly what I'm going through, and so the support group really helped because I was also; you know, somebody else could vent on me, and that made me feel better, because I was helping somebody else out.

\section{Reunion-Ambiguous Presence}

The second phase of ambiguous loss occurred at reunion, during which both reservists and family members were looking forward to returning to the life they knew together before the deployment. However, although most expected an initial adjustment period and changes in one another, many feelings of loss could not have been expected or predicted. Reservists described feeling disconnected psychologically, and many families experienced boundary ambiguity in the form of ambiguous presence. Although the reservist was physically present, family members said that it seemed as if the reservist was psychologically absent. The major themes uncovered from interviews with family members and reservists about the reunion phase revealed boundary ambiguity around the resumption of roles and responsibilities at home and at work, relational communication and expectations, and the soldier-to-civilian transition.

Resumption of roles and responsibilities. Making decisions and assigning roles within the household generated heightened boundary ambiguity for families during deployment. After reunion, the ambiguity around roles and decisions remained, even though the reservist had returned. Family members felt hesitant about asking their reservist to resume certain roles, as they felt unsure of whether the reservist was ready to take back some of his or her roles or of exactly how much more time the reservist needed. Reservists also wondered about how to take up roles without interfering with the family members' new routine and how exactly to fit back into the family. Charlie, a reservist married for 5 years, stated, "My wife was used to running things her way, and I was used to running things my way. Then we had to come back together and learn how to be one again. So that was difficult." Ambiguity around resuming roles was also found between reservists and parents. Tom, a reservist living with his parents, stated,

The hardest part about coming back and getting readjusted was probably redefining roles, like in my family. Knowing what was supposed to be done and what my job was . . what my position really was, what my role was. I had no responsibility when I came back, which made it kind of uncomfortable, just kind of sitting around.

Relational communication and expectations. Deployment forced the family members and their reservist to live without one another for an extended period of time, and as a result each individual had become more closed in communicating thoughts and actions. The struggle to communicate about issues such as roles and decisions appeared to be prevalent in couples but not in parent/child pairs. A common adjustment strain for couples was the transition from a closed communication system to an open communication system. Because the reservist was not around, the spouse had not needed to communicate about the daily activities and to clarify schedules. The communication became more discretionary in terms of what information was important or relevant to mention to the reservist. However, 
after reunion, this closed communication system exacerbated boundary ambiguity around functioning as a couple as opposed to as an individual. It took time for both the reservist and the spouse to clarify the boundary around them as a couple in terms of checking out each other's needs and preferences and engaging in joint decision making. Jennifer, the wife of a reservist for 3 years, stated,

I would say that while he was gone, um, I was able to be ... a lot, uh [sighs], I guess selfish is the right word, 'cause I didn't have to worry about what his plans were, I didn't have to cook dinner for him [laughs slightly]. It was all just about me and what I wanted to do. I could, I could decide at the last minute, but now ... I've got to start considering two people again in my plans and taking care of him. So ... that's definitely not one of the high points. But it's, it's worth it [laughs].

During a separate interview, Jennifer's husband, Eric, reflected similar sentiments:

I think the separation that we had, it forced us both to become very independent again, and so now we are having to deal with that. We both had to become very independent. It's made for some difficult situations here at home and some butting of the heads. I think there was some anxiety about our expectations of each other once we did get back together.

This process of redefining the boundary from individual to couple was particularly challenging for newly married couples, who had less experience in marking and clarifying the boundary around themselves. Parents and reservists seemed to struggle a little with managing the boundary around closeness and individuation. As Carol, the mother of a 20-year-old reservist, stated,

I mean, just knowing he is home and you want to be with him 24 hours, just because you have missed him, and you can't because you know that's not what he wants. And he has kind of his own life that he has to fit back into and adjust to things.

Soldier-to-civilian transition. For some reservists, the boundary ambiguity around roles and relationships was compounded by the struggle to make the switch from soldier to civilian once they had returned home. This struggle resulted in high levels of ambiguous presence for families. It was troublesome for family members when the reservist returned home physically but did not seem the same psychologically. The family members felt as if they hadn't gotten back the same soldier who had left. Sarah, engaged to a reservist, commented,

His behavior was pretty irrational at times. He had a lot of obvious anger; you could just tell he was just not himself. And for me, I was trying to understand and figure out why, what was happening. We argued a lot.

After living in a war zone for over a year, the reservists had become accustomed to military life, and approximately half of the reservists we interviewed disclosed that they had been having a hard time letting their guard down since they had returned home. Greg, a married reservist with young children, stated, "The hardest thing for me was ... I was used to Iraq, looking over my shoulder all of the time, noticing everything about the environment. . . . I didn't feel comfortable going out in public with all of the people." A single reservist, Henry, explained his experience of ambiguous presence by saying, "Physically, I was fine, but it felt weird being home, though, not being in a bad environment anymore." Reservists and family members no longer mentioned boundary ambiguity between civilian life and military life after the first wave of data collection, which led us to conclude that the reservists had adjusted to being out of a war zone within the first 4 weeks after reunion.

\section{Factors Affecting Boundary Ambiguity Levels}

Personal characteristics. Reservists who seemed to value control in their lives did not adjust as quickly as did those who were more relaxed and more willing to allow problems to work themselves out. For instance, Eric, a reservist of 12 years, struggled for several months with boundary ambiguity related to his job. When he returned from deployment to his job as an engineer, many facets of his workplace had changed, including coworkers, administration, and procedures. Eric expressed extreme frustration and confusion, because he could not get a clear idea of the hierarchy or what his company expected of him. He made several attempts to resolve the ambiguity by asking lots of questions and even talking to his boss and threatening to quit. Ultimately, the boundary ambiguity related to his job seemed to be resolved when he was accepted into the company's management training program, which provided him with a great deal of structure and predictability as well as a chance to be in a position with more power.

Returning to work. For most families, boundary ambiguity was greatly reduced when their reservist returned to civilian employment. The return to work seemed to help family members restabilize roles and relationships by creating a routine or returning them to a familiar (predeployment) routine, which reduced ambiguity. Spouses of reservists also expressed a desire for their reservist to return to work as a means of reestablishing a routine. Cindy stated, "I imagine once he goes back to work, it'll kind of go back to the way it was before he left."

However, for a few families, boundary ambiguity remained fairly high due to work. Many reservists experienced setbacks, such as experiencing difficulty in finding employment, returning to a different position that was unfamiliar, being laid off, or feeling unhappy in their job. These setbacks fostered feelings of loss and prolonged ambiguous presence by delaying psychological adjustment for the reservist. Boundary ambiguity surrounding work was often related to financial stressors, which created relationship stress and, in turn, struggles with sharing roles Another wife, Sue, was quite angry because she felt her husband wasn't trying hard enough to find work, and they were beginning to struggle financially. "I expected him to want to take time off. .. . As far as I was concerned, that was fine," she explained. "That time was up, like, middle of July. Let's get moving, now. Let's get back to work and and get on with life." Because struggles with employment were varied and, in some cases, ongoing, boundary ambiguity related to work appeared and dissipated differently for all the participants, depending on their reservist's work status. 
Duration of ambiguity. The amount of time needed to resolve boundary ambiguity after reunion was moderated by life events and by the transition to work. Initially, most spouses and reservists experienced medium-to-high levels of boundary ambiguity. For most, the perceived boundary ambiguity dissipated around 6 weeks following the reservist's return to civilian employment, which helped to establish a routine.

However, for a few participants, life events external to reunion-such as divorce, marriage, health problems, or changing jobs-made finding a routine more difficult. As with all major life events, there were many adjustments in terms of roles and expectations. Experiencing life events in addition to the major adjustment of reunion seemed to create a pileup effect of stressors for families. These additional life changes prolonged and exacerbated the perceived boundary ambiguity.

Ambiguous presence had implications for overall adjustment. Participants with higher perceived levels of boundary ambiguity also reported greater difficulty in adjusting after reunion. That is, those participants expressed more difficulty in returning to life as they felt it should be.

\section{Coping With Ambiguous Presence}

Participants reported coping strategies for dealing with ambiguous presence similar to those for dealing with ambiguous absence, such as talking with those who understood their situation and communicating with one another when there were problems. Although frequency of contact with the FSG was reduced after reunion, family members who remained involved with the FSG stated that speaking to other military family members was an effective form of support. Similarly, reservists mentioned that talking to other reservists was helpful because they understood the deployment experience.

\section{Discussion}

Boundary ambiguity during deployment was mostly associated with concern over the reservist's safety and the redistribution of roles and responsibilities, which are the two most commonly cited stressors in the deployment literature (Bell \& Schumm, 1999; Vormbrock, 1993; Wood et al., 1995). Most families kept their reservist psychologically present during deployment by keeping family boundaries only partially closed. In his famous study on soldiers and families of World War II, Hill (1949) found that families that kept their boundaries only partially closed in terms of reassigning household responsibilities and maintaining a companionable relationship managed the stress of deployment and reunion well. However, families that kept their boundaries completely open during the deployment adjusted poorly to the deployment, whereas families that closed their boundaries completely adjusted well during deployment but struggled upon reunion.

In this study, the degree to which a family closed its boundaries seemed to fluctuate on the basis of the level of ambiguity the family was experiencing. With regard to the ambiguity surrounding their reservist's safety and well- being, family members attempted to keep the boundary very open, so as to obtain as much information as possible. However, as information came in to the family regarding bombings and attacks, family members seemed to experience greater levels of ambiguity in terms of their reservist's safety and well-being. As a result, it appears, families closed their boundaries to some degree by not watching the news and by trying to limit the amount of incoming information. The reservists also appeared to make attempts to regulate the boundaries by limiting the amount of information they provided to their families.

Also of interest was how family members shifted from ambiguous absence to ambiguous presence. A few weeks prior to their reservist's return, family members experienced a brief transition period in which their ambiguity shifted from reservist safety and household management to ambiguity surrounding the reservist's personality and behavior upon return. This transition period is similar to the redeployment stage of the emotional cycles of deployment (Pincus et al., 2006). During this period of transition, reservists became more psychologically present within the family, as family members began to envision how their reservist would fit back within the new evolved family system. This process of making the reservist more psychologically present prior to his or her arrival may help to ease or to prepare the family for reunion.

Following reunion, many spouses and reservists reported boundary ambiguity surrounding the redistribution of roles and responsibilities, which is one of the most commonly cited stressors in the reunion literature (Caliber Associates, 1992; Drummet et al., 2003; Riggs, 1990). The redistribution of roles and responsibilities was hampered if spouses and reservists had a difficult time transitioning from a closed communication system to an open communication system.

Overall, during deployment, both parents and spouses/ significant others experienced similar levels of boundary ambiguity specifically related to safety, but parents had lower levels of boundary ambiguity related to redistribution of roles and responsibilities. In terms of boundary ambiguity related to reunion, spouses and significant others clearly experienced much higher levels than did parents. The fact that boundary ambiguity was higher for couples compared with parents may be a result of the differences in roles and expectations found in a couple's relationship compared with those found in an adult child/parent relationship, as well as of the fact that most parent/child pairs did not live together.

A key event that seemed to help dissipate boundary ambiguity was the reservist's return to work at his or her civilian job, which helped to establish a more familiar routine for the family. Many reservists and family members spoke about the return to work as something that helped to "normalize" their lives. However, most reservists waited a few weeks before they returned to work, in order to rest, physically and psychologically. This delay may put soldiers in a bind between individual well-being and overall family well-being, particularly if a family member is urging them to return to work before they are ready.

To cope with boundary ambiguity, most families cited 
taking the following actions: seeking information, attending the family support group, and talking to others whom they felt understood their situation. These coping strategies are consistent with those described in other research that has examined positive coping strategies for boundary ambiguity in other populations (Afifi \& Keith, 2004; Boss, 2004; Golish \& Powell, 2003).

\section{Limitations and Future Research}

There are several limitations to this study. First, due to the small convenience sample from only one reserve unit, findings should be treated as suggestions for issues that may be worthy of additional investigation, rather than as definitive statements about the experiences of reserve families. In addition, several participants who dropped out early from the study reported poor adjustment and relationship problems, which suggests that the retained sample may have been better adjusted than was the entire pool.

The process of assessing the level of ambiguity at each time point had limitations as well. Although the coding had good interrater reliability, future longitudinal studies will need to refine the quantification of boundary ambiguity. Additional longitudinal studies are needed to further our understanding of military families and their adjustment patterns. More specifically, these studies should evaluate how family adjustment is impacted by external family contexts, as outlined by Wiens and Boss (2006). Although families usually have less control over these contexts, they nonetheless play a role in a family's resiliency and perception of boundary ambiguity.

\section{Clinical and Policy Implications}

The results from this study suggest that, during deployment, FSGs may be recommended by clinicians. Family members reported that the FSG was one place where they felt validated, were understood, and could obtain information that helped to reduce their perceived boundary ambiguity. If no FSG exists in the community, clinicians should be inclined to initiate a military support group that will help military families through the deployment and will offer them information and workshops on stress management. Clinicians who work with military families following return should pay specific attention to the boundary ambiguity that families may be experiencing during this transitional phase and should address this through discussion of each person's expectations in terms of roles, responsibilities, and relationships. Clinicians can also help families reduce their boundary ambiguity by encouraging them to reestablish routines that will create predictability in the lives of family members. Finally, clinicians could create and distribute conversation start-up scripts that would help couples or families begin conversations about their expectations and roles, once their soldier returns.

Unit administrators and FSG leaders were significant sources of information and support for the families in this study, which reduced perceived levels of boundary ambiguity. By all accounts, the FSG leader for this particular unit was exceptional and very energetic in seeking and distrib- uting information. It is unclear, however, how useful FSGs that lacked such a dynamic and helpful leader would be for families. It is, therefore, necessary for units to ensure that support group leaders themselves have guidance and access to useful materials, so they may better serve families.

Many family members lived far from the unit headquarters, either because they were parents of reservists who were living elsewhere or because they were family members of reservists who had been assigned to the unit as individual augments from distant states. Even some families in the local area had to travel $2 \mathrm{hr}$ for meetings. Resources that help family members to have full access to the FSG would be very helpful. Making sure, for example, that groups have easy access to and the ability to pay for teleconferences, unit websites, electronic mailing lists, and webcasts might improve access for families in general.

In conclusion, reservists and their families appear to experience issues related to deployment and reunion-such as redistribution of roles, communication, and safetysimilar to those experienced by active duty soldiers and families. However, it seems that reservists and their families confront these issues with less experience and with less support than do active duty soldiers and their families. Nonetheless, the issues faced by reservists and their families entail boundary ambiguity. Strategies such as the reservist's return to civilian employment appear to be an important stabilizing resource. The ability of families to address and reduce this boundary ambiguity has a direct impact on their overall adjustment to deployment and reunion.

\section{References}

Afifi, T. D., \& Keith, S. (2004). A risk and resiliency model of ambiguous loss in postdivorce stepfamilies. Journal of Family Communication, 4, 65-98.

Bell, D. B., \& Schumm, W. R. (1999). Family adaptation to deployments. In P. McClure (Ed.), Pathways to the future: A review of military family research (pp. 109-118). Scranton, PA: Marywood University, Military Family Institute.

Boss, P. (1986). Family stress: Perception and context. In M. Sussman \& S. Steinmetz (Eds.), Handbook on marriage and the family (pp. 695-723). New York: Plenum Press.

Boss, P. (2002). Family stress management. Newbury Park, CA: Sage.

Boss, P. (2004). Ambiguous loss research, theory, and practice: Reflections after 9/11. Journal of Marriage and Family, 66, 551-566.

Boss, P., \& Greenberg, J. (1984). Family boundary ambiguity: A new variable in family stress theory. Family Process, 23, 535546.

Caliber Associates. (1992). A study of the effectiveness of family assistance programs in the Air Force Reserve during Operation Desert Shield/Storm: Final report (Rep. No. F49642-88D5003). Fairfax, VA: Author.

Caliber Associates. (1993). Study of impact of Operation Desert Shield/Storm (ODS/S) on Navy families and effectiveness of family support programs in ameliorating impact: Vol. 2. Final report (Rep. No. N0600-91-D-0364). Fairfax, VA: Author.

Coalition Information Centers. (2001). The global war on terrorism: The first 100 days. Retrieved April 23, 2007, from http:// www.whitehouse.gov/news/releases/2001/ 12/100dayreport.html 
Cohen, J. (1960). A coefficient of agreement for nominal scales. Educational and Psychological Measurement, 20, 37-46.

Drummet, A. R., Coleman, M., \& Cable, S. (2003). Military families under stress: Implications for family life education. Family Relations, 52, 279-287.

Dunning, C. M. (1996). From citizen to soldier: Mobilization of reservists. In R. Uranso \& A. Norwood (Eds.), Emotional aftermath of the Persian Gulf War (pp. 197-225). Washington, DC: American Psychiatric Press.

Fleiss, J. L. (1973). Statistical methods for rates and proportions. Oxford, England: Wiley.

Global Security. (2007). U.S. Forces Order of Battle. Retrieved January 24, 2007, from http://www.globalsecurity.org/military/ ops/iraq_orbat.htm

Golish, T. D., \& Powell, K. A. (2003). "Ambiguous loss": Managing the dialectics of grief associated with premature birth. Journal of Social and Personal Relationships, 20, 309-334.

Hill, R. (1949). Families under stress: Adjustment to the crises of war separation and reunion. New York: Harper.

Hogancamp, V. E., \& Figley, C. R. (1983). War: Bringing the battle home. In C. R. Figley \& H. I. McCubbin (Eds.), Stress and the family: Coping with catastrophe (Vol. 2, pp. 148-165). New York: Brunner/Mazel.

Hoge, C. W., Castro, C. A., Messer, S. C., McGurk, D., Cotting, D. I., \& Koffman, R. L. (2004). Combat duty in Iraq and Afghanistan, mental health problems, and barriers to care. New England Journal of Medicine, 351, 13-22.

Kerner-Hoeg, S., Baker, S. Lomvardias, C., \& Towne, L. (1993). Operation Restore Hope Survey of Army spouses at Fort Drum, New York: Survey methodology and data book. Fairfax, VA: Caliber Associates.

Lavee, Y., McCubbin, H., \& Patterson, J. (1985). The double ABCX model of family stress and adaptation: An empirical test by analysis of structural equations with latent variables. Journal of Marriage and the Family, 47, 811-825.

McCubbin, H., \& Patterson, J. (1983). The family process: The double ABCX model of adjustment and adaptation. In H. McCubbin, M. Sussman, \& J. Patterson (Eds.), Social stress and the family: Advances and development in family stress theory and research (pp. 7-37). New York: Haworth Press.

Miles, M. B., \& Huberman, A. M. (1994). Qualitative data analysis (2nd ed.). Thousand Oaks, CA: Sage.

Military Homefront. (2005). 2005 demographic report. Retrieved February 7, 2007, from http://www.militaryhomefront .dod.mil/portal/page/itc/MHF/MHF_DETAIL_0?current_ $\mathrm{id}=20.20 .60 .70 \cdot 0 \cdot 0.0 .0 .0$

Patton, M. Q. (2002). Qualitative research and evaluation methods (3rd ed.). Thousand Oaks, CA: Sage.

Pincus, S., House, R., Christenson, J., \& Adler, L. (2006). The emotional cycle of deployment: A military family perspective. Retrieved February 24, 2006, from http://www.hooah4health .com/deployment/familymatters/emotionalcycle.htm

Quadrennial Defense Review. (2002). Review of reserve compo- nent contributions to national defense. Washington, DC: Office of the Assistant Secretary of Defense for Reserve Affairs.

Rienerth, J. G. (1978). Separation and female centeredness in the military family. In E. J. Hunter \& D. S. Nice (Eds.), Military families: Adaptation to change (pp. 169-184). New York: Praeger.

Riggs, B. (1990). Routine work-related absence: The effects on families. Marriage and Family Review, 15, 147-160.

Rohall, D. E., Segal, M. W., \& Segal, D. R. (1999). Examining the importance of organizational supports on family adjustment to Army life in a period of increasing separation. Journal of Political and Military Sociology, 27, 49-65.

Rosen, L., \& Moghadam, L. (1990). Matching the support to the stressor: Implications for the buffering hypothesis. Military Psychology, 2, 193-204.

Saldana, J. (2003). Longitudinal qualitative research. Walnut Creek, CA: AltaMira Press.

Sandelowski, M. (2000). Whatever happened to qualitative description? Research in Nursing \& Health, 23, 334-340.

Segal, M. W., \& Segal, D. R. (2003). Implications for military families of changes in the Armed Forces of the United States. In G. Caforio (Ed.), Handbook of the sociology of the military (pp. 225-233). New York: Kluwer Academic/Plenum.

Stretch, R. H., Marlowe, D. H., Wright, K. M., Bliese, P. D., Knudson, K. H., \& Hoover, C. H. (1996). Post-traumatic stress disorder symptoms among Gulf War veterans. Military Medicine, 161, 407-410.

Sullivan-Bolyai, S., Bova, C., \& Harper, D. (2005). Developing and refining interventions in persons with health disparities: The use of qualitative description. Nursing Outlook, 53, 127-132.

U.S. Government Accountability Office. (2006, September). Military personnel: DOD and the services need to take additional steps to improve mobilization data for the reserve components (GAO Publication No. GAO-06-1068). Retrieved January 22, 2007, from http://www.gao.gov/docsearch/abstract.php?rptno= GAO-06-1068

Vormbrock, J. (1993). Attachment theory as applied to wartime and job-related marital separation. Child Development, 114, 122 144.

Wiens, T. W., \& Boss, P. (2006). Maintaining family resiliency before, during, and after military separation. In C. A. Castro, A. B. Adler, \& T. H. Britt (Eds.), Military life: The psychology of serving in peace and combat: Vol. 3. The military family (pp. 13-38). Westport, CT: Praeger Security International.

Wood, S., Scarville, J., \& Gravino, K. (1995). Waiting wives: Separation and reunion among Army wives. Armed Forces \& Society, 21, 217-236.

Yerkes, S., \& Holloway, H. (1996). War and homecomings: The stressors of war and of returning from war. In R. Uranso \& A. Norwood (Eds.), Emotional aftermath of the Persian Gulf War (pp. 25-42). Washington, DC: American Psychiatric Press.

Received October 20, 2006

Revision received June 5, 2007 Accepted June 6, 2007 